\section{Transnational Pathways to English Higher Education}

\section{JANet ILIEVA}

Janet Ilieva is on the staff of the Higher Education Funding Council for England (HEFCE), United Kingdom. E-mail: j.ilieva@hefce. ac.uk. Note: a full version of this article is titled "Directions of Travel: Transnational Pathways into English Higher Education" and it is available on the HEFCE Web site at: http://www.hefce.ac.uk/pubs/ year/2014/201429/.

$\mathrm{T}$ There is a wealth of anecdotal evidence that suggests that transnational education (TNE) is increasingly used as a recruitment tool by higher education institutions. TNE is broadly defined as education provision delivered in a different country from that of the education institution. This research is the first attempt to estimate the contribution of UK TNE to first-degree programs in England. TNE programs leading to enrollments in England are referred to as transnational pathways; respectively TNE students who have progressed from TNE programs to courses delivered onshore are referred to as transnational students. Our analysis shows that in 20I2-2013 over a third of all international entrants-34 percent or 16,500 entrants-to first degree programs in England transferred directly from TNE programs.

\section{TNE is broadly defined as education provision delivered in a different coun- try from that of the education institu- tion.}

The transnational entrants fuelled the growth from China in the period from 2009-20IO to 2012-20I3. Transnational entrants from China increased by 55 percent (almost 3,000 entrants) compared with I8 percent growth-I,000 entrants-in direct recruitment to first-degree programs in England. Malaysia is the second largest country of origin for transnational progressions. About 63 percent $(3,200$ entrants) of the Malaysian students in England used transnational pathways when commencing first-degree programs.

Overall, transnational students from China and Malaysia account for an estimated 70 percent of the total transnational entrants to first-degree programs in England. Except for Singapore, China and Malaysia are among the largest countries for British TNE.

There are some significant differences in the length of study that transnational students spend in England. The majority of transnational entrants from China-66 percent, 5,450 entrants - were enrolled in programs with a reported length of between two and three years in 2012-2013. In contrast, the majority of entrants from Malaysia (56\%) were enrolled in programs of one year or less. The next largest transnational populations came from Nigeria and Hong Kong, which contributed 550 and 500 entrants, respectively. Transnational entrants from Nigeria appear to have mitigated the bigger declines experienced in direct recruitment to first-degree programs.

\section{Shorter Programs lead to Declines in Overall Period OF STUdY}

One of the key characteristics of transnational entrants is that they spend significantly shorter periods of study in England, compared with the standard first-degree population. The highest growth was observed in programs with a duration of one academic year or less, which proportions increased from 28 percent (3,700 entrants) in 2009-2010 to 33 percent $(5,500$ entrants) in $2012-2013$. This shift toward shorter study may be partly attributable to the impact of the global financial crisis of 2008-2009 on middle-class incomes. Shorter programs are more affordable- through savings on tuition fees and lower cost of living associated with shorter period spent abroad-for families who otherwise would have been unable to do so and those whose disposable income declined in the aftermath of the crisis.

\section{Are Transnational Students Contributing to Demand For Postgraduate Programs?}

About a third of all transnational students who started firstdegree programs through transnational programs continued their studies at the postgraduate level. Given the limited time series dating back to 2009-2010, we are only able to track students who commenced first-degree courses in 2009-20IO and 2010-20II and continued into postgraduate programs two years later. Some 5,100 students from the population, who started their first degrees in 20IO-20II, continued at the postgraduate level by $20 \mathrm{I} 2-20 \mathrm{I} 3$. The majority of these students- 82 percent or 4,I30 entrantswere from China.

Of all transnational students from China who started their first degree program in 2009, 59 percent continued their studies at the postgraduate level. We can now attribute 45 percent of the growth in Chinese students enrolling in taught master's degrees in 20I2-20I3, compared with the previous year, to an increase in the number of transnational students continuing their studies at the postgraduate level (I,IOO students). This finding highlights the importance of postgraduate degrees, as a component of student decision making for transnational entrants from China to undergraduate programs. 
At this stage we are unable to establish how many international students from UK TNE programs transfer directly into postgraduate programs in England.

\section{CONCLUSIONS}

China and Malaysia are the countries with the highest proportions of transnational students starting undergraduate degrees in England and are also among the largest TNE markets. While the expected course length of transnational entrants poses some recruitment and financial challenges for higher education institutions, it has also emerged as a cost-efficient route to English higher education for aspiring middle-class families in East Asia. Similarly, shorter programs may have widened the access to English higher education for families who otherwise would have been unable to afford English degrees.

The enabling environment for TNE in East Asia will continue to improve in the long run. Malaysia is the only country in the region whose higher education degrees awarded through TNE are recognized in China. Further harmonization of higher education systems across the region is set to take place with an additional boost through the Association of the South East Asian Nations Economic Community in 2015. While not many students in this region outside Malaysia use transnational routes to English higher education, their number is expected to grow.

Global universities through their TNE provision are more likely to be well embedded in the education landscape of the host country. As a result, they are set to benefit in the long run from increasing intra-regional levels of student mobility, and equally, harness deep and comprehensive collaborative partnerships with institutions in the region.

\section{How Much is a Full}

Professor Worth?-The Challenge of Attracting the Best Talent

\section{Marcelo Knobel}

Marcelo Knobel is a full professor at the "Gleb Wataghin" Physics Institute of the University of Campinas (Unicamp), Campinas, São Paulo, Brazil.E-mail:knobel@ifi.unicamp.br.

$\mathrm{I}$ $\mathrm{n}$ a recent book, Philip G. Altbach and colleagues attempt1 ed a careful comparison of salaries of faculty members in different countries (Altbach et al., eds., Paying the Profes- soriate: A Global Comparison of Compensation and Contracts, Routledge, 20I2). Despite their research, one of the main conclusions of the report was that this kind of information is incredibly difficult to find and even more difficult to analyze, owing to different discounts and benefits provided by each country and the fact that individual career paths are reflected in differentiated salaries. Many countries have been struggling to develop a solid higher education system, and the attraction of young and motivated talent is key to the further development of a culture of excellence-to support the education of future generations. However, in Brazil and in many Latin-American countries there is a strong trend against compensation based on academic merit, particularly in public research-intensive universities. In this article, I will offer the example of a public policy of the State of São Paulo that will certainly affect the attraction of young talent to its universities, putting at risk an effort to build a highquality higher education system, which has been evolving over the last 60 years.

In principle, data regarding salaries and compensations should be easy to track in Brazil, where an "equality" code has governed salaries in the higher education system. Regardless of productivity, impact or success in attracting additional financial resources, policy dictates that faculty members at the same level of their career should receive the same monthly stipend. In practice, the situation is much more complex, not only because there are salary increments for longevity at the institution, but also when remuneration for administrative assignments is added. Furthermore, some faculty members receive additional income from grants or consulting work. To make things more complicated, salaries vary by institution type-private for-profit, private nonprofit public federal, public state, or public municipal.

\section{Limitations AT THE TOP}

A recent debate in Brazil has raised interesting issues related to the salaries of senior faculty at public universities in the state of São Paulo (University of São Paulo-USP, University of Campinas-Unicamp, and University of the State of São Paulo-Unesp), institutions generally considered among the best in Latin America as evidenced in different rankings. Since 2003, responding to federal regulation, the State of São Paulo has tied public-sector salaries to the compensation of its governor, whose compensation represents the maximum salary allowed for a public servant-the socalled "teto" or "ceiling." Not suprisingly, this ceiling can be adjusted down for political expediency, particularly to prevent an increase of state expenditures. It also opens the door to populist-oriented policy, although in truth the governor does not depend on a monthly salary as he/she receives many nonmonetary benefits (housing, driver, meals, etc.). 